\title{
LA PERTURBACIÓN DE HANNAH ARENDT: EL TONO Y LA DISCREPANCIA
}

\author{
Edgar Tello García \\ Ratnakara. Universidad Autònoma de Barcelona
}

\begin{abstract}
RESUMEN / ABSTRACT
Por un lado, el trabajo pretende mostrar de qué modo el "tono" de Arendt en sus trabajos académicos, tal y como lo señalara Scholem en una de sus misivas críticas a la autora, lejos de ser frívolo o burlón (como se apuntaba en esa crítica) produce una brecha perturbadora, por la cual los lectores y las lectoras de Hannah Arendt pueden desvelar hipocresías y actuar con una nueva responsabilidad.

Por otro lado, el artículo señala diversos conceptos filosóficos, algunos ya sometidos a investigación por Arendt, que en sí mismos presentan la fuerza de crear un mundo y unos seres humanos, con la energía teórica y real necesaria como para transformarlos: "pensar", "actuar", "amar", son algunos de ellos. En este último sendero, utilizaremos la ayuda de sus discípulas, Fina Birulés y Marina Garcés.
\end{abstract}

Palabras Clave: Hannah Arendt, tono, filosofía moral, responsabilidad, compasión, historia.

\section{ARENDT'S DISTURBANCE: TONE AND DISSENT}

On the one hand, this paper shows how Hannah Arendt's "tone", far from being "flippant" or "mocking" - as Scholem suggested in a letter to her - creates a necessary perturbation in order to discover hypocrisy. That is the way to act responsibly to interpret our present and, then, face and write the history.

On the other hand, we remark some philosophical concepts that, when used blurredly from different traditions may create a fixed world and people. With Arendt's mastership we analyze them in order to reenergize them. For this task we use the help of some other philosophers as Fina Birulés or Marina Garcés.

KEYWords: Hannah Arendt, Tone, Moral Philosophy, Responsibility, Compassion, History, Marina Garcés. 
Lo que objeto es ese tono despiadado, a menudo poco menos que burlesco y malicioso, con que tu libro trata asuntos que tocan la fibra más sensible de nuestras vidas. [...] por eso siento escasa simpatía hacia ese tono -tan adecuadamente expresado con el término inglés flippancy ['ligereza'] que tan a menudo empleas a lo largo de tu libro. Para referirse al asunto del que hablas es tremendamente inadecuado.

En circunstancias como estas, ¿no habría habido lugar para algo que yo sólo puedo describir con el modesto término alemán Herzenstakt? ['cordial delicadeza']

Carta de G. Scholem (Arendt 2005, p. 139).

\section{La perturbación Arendt: desde el "amor" al pueblo judio hasta la historia}

RR Comenzamos ocultando la voz de Arendt, tras Scholem, con el fin de señalar el cariz que toman las palabras dichas y copiadas, condenadas si se quiere a la finitud, pero eternamente presentes y resonantes. Decir que Hannah Arendt es una de las más conspicuas atizadoras de la cultura ya no es hoy arriesgado, aunque quizá lo sea algo más el afirmar que ella es una de las primeras autoras en poner bajo análisis conceptos tan arcangélicos como el de los "derechos humanos", el de la condición plural de los seres humanos o el de la "compasión" y la "solidaridad" entre ellos". En este sentido, la lectura de sus trabajos resulta de una abrumadora actualidad por dos motivos: en primer lugar, por las evidentes circunstancias políticas y el auge de las extremas derechas, que no pretendemos analizar aquí; en segundo lugar, por la transgresión de los mismos valores que Arendt se encargara de estudiar en sus diversos trabajos, desvelando con su tono distanciado, un cierto tipo de hipocresía, o costumbre bondadosa (moralista), de la que no quedaba al margen la posibilidad del mal. Para Arendt, la "buena voluntad" va a parar al "imperativo categórico" kantiano, y de aquí, "por una puerta trasera", a la obediencia (Arendt 2014, p. 93). Es difícil separar estas aserciones de la escena matriz anotada en el epígrafe de este texto, en la que Arendt se defenderá de los ataques de su "falta de amor". Cuando Scholem apela a esa "buena voluntad" que, en resumen, es la única compañera fiable de la justicia, en el fondo está introduciendo ese matiz de sumisión al que Arendt alude. De hecho, aquello que puede luchar contra la banalidad no es otra cosa que la "veracidad", buscada en común, de un modo puramente socrático, al margen de escuelas y leyes, capaz de dotar del antídoto contra la "uniformización" del pensamiento, o Gleichschaltung (Birulés 2017, p. 26).

Más allá de la búsqueda de la ignorancia propia platónica, y del vacío de opiniones necesario para poder llenar de nuevo el espíritu, en algún momento la autora debe reaparecer en la historia para tomar y liberar el control de conceptos que estaban a

Vid. entre muchos otros trabajos, Arendt (1999, 2005, 2014, 2017a). Birmingham (2017) para la crítica de los derechos humanos o Tello García (2018) para la de la compasión. 
disposición de un único mundo e historia posibles, si pretende romper el silencio ante el cual se piensa que los hechos hablan por sí solos (Arendt 2014, p. 104; Koselleck 2016,p. 18). El objetivo es dotar de sentido a la historia que hasta el momento no la tenía, o cuando menos, dotar de la posibilidad de verbalización a un cuento que se escabulle hacia el irracionalismo. Pese a las críticas recibidas por lo neokantianos, si se nos permite, en el universo de la presencia, el amor no es de este mundo; mientras que la paz del encerramiento místico rehúye toda explicación, y por consiguiente, también todo recuerdo y pensamiento ${ }^{2}$. La idea de una historia original, lineal y cimentada en la verdad, tampoco. La tarea no es grata, puesto que conlleva una "responsabilidad", que en este caso no es sino una "instancia última" consistente en inscribirse en un período en el que hubiese sido más sencillo borrarse, rompiendo la convergencia entre historia y concepto, mediante un distanciamiento que comienza con el enfriamiento de la manía pasional y heroica, desde la filosofía moral (Koselleck 2016, pp. 33 y 121) . $^{3}$

Al mostrar esa perturbación del tono -por utilizar la expresión asociada al puer robustus, que desplaza, rompe, defiende, discute en la fragmentación de las experiencias límite, para bien o para mal- desvela las carencias de solidez y coherencia de un discurso filológico, y gracias a ello (seamos optimistas) lo hace avanzar. Traigo a colación la ambigua figura del puer robustus -del tipo nomocéntrico, según la exhaustiva tipología de Dieter Thomä (2018, p. 22) -para ilustrar que la misma persona de Arendt, desde las amables y admonitorias palabras de Scholem, también está siendo amenzada, muy a su pesar, con convertirse en una de sus actuantes marginales. Al perder su inclusión en un modelo de identidad colectiva (judía) - o ser amenazada subrepticiamente con esa expulsión, tras la publicación de Eichmann en Jerusalén-, Arendt es empujada a reconfigurar (comprender) el orden desde el que se la invita a ser excluida o amansada por su comunidad.

Con el fin de atacar el silencio impuesto por el liberalismo del miedo - usando la fórmula de Judith Shklar-, Arendt reafirmará su amor, o si se prefiere, su filosofía. Ya que el asesinato de más de seis millones de judíos es un asunto traumático, el tema debe ser tratado con delicadeza, sugiere dramáticamente Scholem. La respuesta implícita de Arendt, en modo alguno delicada, conlleva la idea de que para reflexionar sobre una historia es necesidad romper su línea narrativa para analizarla, obtener múltiples perspectivas y generar diversas lecturas. Eichmann en Jerusalén propone que detrás de la historia, del ser y de toda una Weltanschauung del mal, no hay una trascendencia, sino banalidad. La réplica implícita es que banalidad es hablar de aquello de lo que es preferible no hablar (bajo el disfraz de la cordialidad). No está en juego "la historia de la salvación" que no es más que el reflejo de la crisis o incapacidad para escribir esa historia; y si no hay nada que ganar, el devenir enseña que tampoco hay un símbolo redentor a modo de esperanza (Barth 1998, p. 32). Esta tarea desgarradora de prueba y

2 Los místicos veían la necesidad de "oscurecer la memoria en todo discurso y noticia", con el fin de apartarse de esa afición a la presencia, tal y como nos recuerda San Juan de la Cruz en la "Subida al Monte Carmelo) (Andrés 2015, p. 297).

3 Sigo a este autor en las reflexiones que se expresan a continuación. 
error no siempre puede realizarse Herzenstakt, pese a que sí debe realizarse con amor, con el fin de "conmocionar y reconfigurar el orden" desde el que se la ataca (Thomä 2018, pp. 23 y 27). Y en esa rotura (Illusionstörung, si se prefiere), no hay lugar para la cordialidad, pues se está atacando la corrupción del sistema que ha producido esa misma historia. Los arrolladores acontecimientos de la Segunda Guerra Mundial ya no forzaban tanto a "tomar partido", cuanto a comenzar un verdadero desmantelamiento del sistema de coordenadas, convenciones y conceptos del "mundo de ayer". Más que de "conocer la historia para no repetirla", se trataría de comprenderla, es decir, presionarla, plegarla sobre sí misma, forzarla, destruirla y destruirse, junto a ella y a sus protagonistas que como Zweig, por fidelidad a lo cómodo no habían sido capaces de llevar a cabo alguna de las etapas de esta tarea (Arendt 2005, p. 37). Y a diferencia de lo que se nos pretende hacer creer, la persona que contribuya a esa labor no será "malvada", sino "poderosa" en un espectro que habría quedado (peligrosamente) vacante y ahistórico.

Como el objetivo es mostrar este cambio radical por medio del tono utilizado por Arendt, y equipararlo a un "giro" en el mismo sentido con el que los humanistas observaban la cultura, nos hallamos en ese terreno cordial en el que la "dulce afabilidad", por mucho que sea identificada en ocasiones con la "indiferencia", o incluso con la frivolidad, o la ironía, abre el paso a una naturalidad, en un mundo más amplio y múltiple (Byung-Chul Han 2018, p. 213) ${ }^{4}$. Veamos un ejemplo concreto de estas perversiones lingüísticas (retóricas) a partir de la respuesta que Arendt escribe a su colega, el experto cabalista Gershom Scholem: la técnica de Arendt es la de la retórica concessio, en la que, de paso, redirige su mensaje hacia una definición del afecto y el amor. Se trata de una respuesta a una carta, escrita en tono paternalista, que Scholem le dirige a modo de crítica, a raíz de la aparición de su Eichmann en Jerusalén. Podemos resumir los reparos de Scholem en la crítica al tono de Arendt, frívolo ("poco menos que burlesco y malicioso"), a la hora de tratar el Holocausto judío y la responsabilidad del acusado. Por eso, concluye Scholem, "siento escasa simpatía hacia ese tono". ¿No podría la autora haber "amado más" a su pueblo?, le demanda Scholem.

Tienes bastante razón: yo no me siento movida por ningún 'amor' de esa clase, y ello por dos razones: yo nunca en mi vida he 'amado' a ningún pueblo ni colectivo, ni al pueblo alemán, ni al francés, ni al norteamericano, ni a la clase obrera, ni a nada semejante. En efecto, sólo ‘amo' a mis amigos y el único género de amor que conozco y en el que creo es el amor a las personas (Arendt 2005, p. 45).

Acaso, Arendt nos dé la clave de su distanciamiento a la hora de escribir, a partir de la crítica que expresa respecto a los teóricos del sionismo. Parece compartir con ellos un desprecio equidistante respecto a las masas, a la par que una paradójica y "verdadera afinidad con ellas". Puede ser confuso este retorcimiento y la descontextualización de las palabras, pero el concepto de "tono" es amplio y refiere al acercamiento a conceptos

$4 \quad$ La idea de "giro" ("swerve"), la utiliza Stephen Greenblatt (2012) en su trabajo sobre Poggio y el humanismo. En él me inspiro para la comparación. 
que son amplios y multiformes, con diversas perspectivas. Por supuesto que Marx no queda exento de culpa ante esa "confusión”, capaz de crear unas dinámicas en la tradición filosófica "responsables de la mala comprensión de la políticia; dinámicas que, en el fondo, responden a una estrategia de 'esquivamiento' y ocultamiento de los elementos "perturbadores"' que no serían otros que la singularidad, la temporalidad, la diferencia o la pluralidad de una vida en común (Forti 2017, p. 125). De este modo se anulaba la categoría histórica y se interrumpía el tiempo en el presente, algo que volvía muy dificultoso el análisis frío de los hechos, tal y como la autora pretendía. Cuando escribe su descripción de Theodor Herzl, Arendt se nos aparece en ese presente, pero ahora desde la actualidad confusa, para traernos la imagen de un verdadero líder populista:

Herzl compartía el desprecio hacia las masas y una verdadera afinidad con ellas. Y al igual que aquellos mismos políticos, era más una encarnación que un representante de los estratos de la sociedad a la que pertenecía (Arendt 2005, p. 63)

Hablando de Herzl, Arendt expresa un juicio filosófico (de cuño heideggeriano), algo difícil de entender fuera de los límites de la época y del artículo en el que fue escrito: "lo que ellos [los judíos] necesitaban no era sólo una guía para la realidad, sino la realidad misma; no simplemente una clave para la historia, sino la experiencia misma de la historia" (Arendt 2005, p. 65). Una reflexión no menor sea el hecho de considerar a Arendt una rara avis perteneciente al ámbito de los discrepantes. Como ella misma sugería, no sin ser inmune a ese tono entre irónico y academicista que empleaba, "una opinión unánime es un fenómeno muy inquietante, característico de nuestra época moderna de cultura de masas [...]. Una opinión pública unánime tiende a eliminar físicamente a los discrepantes" (Arendt 2005, pp. 81-82).

Ya que vivimos en la edad de la psicología y el capitalismo desenfrenado, en una conjunción paradójica, puede resultar necesario resaltar la brecha que Arendt introdujo en el lenguaje de la justicia y la culpa, señalando brechas por las que todavía es posible escapar hacia un espacio común, en el cual actuar y criticar ${ }^{5}$. Richard Sennett, desde la sociología interpretativa, justifica este "giro" suprasegmental en la expresión de ciertos conceptos desde el ejemplo de ciertos profesionales sociales (de clase superior a la de los pobres de los que se ocupaban), donde la "jerga puede ser degradante" y "puede tratar a los pobres como bienes deteriorados"; mientras que "la caridad misma tiene poder para herir; la piedad puede engendrar menosprecio; la compasión puede estar íntimamente ligada a la desigualdad” (Sennett 2018, p. 33). Ello es así cuando

$5 \quad$ El auge de las disciplinas orientales, la filosofía perenne y práctica, junto con las celebraciones del segundo centenario del nacimiento de Marx (2018), nos sitúan sobre la pista de este nuevo pensamiento que aúpa conceptos (caridad, piedad, compasión) sobreutilizados por la religión y el discurso laico, con fines dispares. Propondré, a continuación, el ejemplo más detallado de Sennett (2018, p. 33). En El Mundo, (12 de noviembre de 2018) aparece una noticia en el que la actual Ministra de Educación, Isabel Celáa, propone la obtención del bachillerato "con suspenso" para "no bajar la autoestima" de los alumnos, ni dañar su "consistencia emocional". 
el lenguaje pierde su sentido y su tono crítico, permitiendo que la realidad que crea, y los habitantes que la conforman, vean atacados fácilmente su trascendencia desde la vacuidad de la producción ${ }^{6}$. Que alguien no vea con simpatía el tono de la posible respuesta, puede hacernos pensar si, llanamente, ve con simpatía la respuesta.

\section{Pensamiento, “opiniones unánimes" y otras perturbaciones}

Acaso sea verdad que ya no es necesaria una crítica de las verdades mejor conocidas porque hasta nosotros solo han llegado sus escombros (Arendt 2017b, p. 20), pero también es cierto el valor que Arendt le otorga a la doxa en un mundo común en el que las amistades hablarían de temas que interesan en común, sin que un valor acabara imponiéndose sobre el otro. No hay una verdad válida para todos, sino muchas voces contrapuestas y muchas razones distintas (logoi) (Birulés 2017, p. 19). ¿Entonces cuál es el motivo del alzamiento de la voz por encima de las de los demás? Comentando la filiación de Rusia en los primeros estadios del sionismo, Arendt vuelve a vislumbrar en la cosmovisión general judía, un aspecto cínico que, según ella, comenzaría en ese instante -y que, podríamos decir de una forma laxa, ya no se abandonaría hasta nuestros días: "por primera vez hay una nota de cinismo en las esperanzas judías" (Arendt 2005, p. 83). Puede tratarse de un punto de inflexión, hasta la aparición de la perturbación del mal. Hasta que no llegue su presencia debemos esperar, pero alertando y combatiendo en el mismo tono combativo. Con el objetivo de ver la diferencia, podemos hacer una analogía con el tono de un presidente (Trump) "que infringe todo aquello que en función de criterios estrictamente morales se considera buen comportamiento" (Thomä 2018, p. 477). En el momento en que una voz perturba el compromiso social, debe surgir otra a la que aferrarse, y para ello debe de resultar visible. Sennett, a quien ya hemos aludido arriba, alcanza su teoría sobre el respeto a raíz de un accidente que lo imposibilita para su carrera musical; no obstante, el posicionamiento más coherente suele ganarse llamando la atención sobre un hecho que revierte en contra de dicha humanidad. Y en esta labor, la forma en la que se lanza el mensaje debe ser igual de llamativa que la de la perturbación contra la que se alza. En este sentido, Arendt nos lega la paradójica lección de que el pensar puro, en ocasiones, puede alinearse sencillamente con el no pensar (Birulés 2007, p. 210). Para ello el tono usado puede variar desde la admonición paternal, inaudible, hasta el grito frío, analítico, sin corazón en apariencia, que desvele e incomode el archiconocido silencio cómplice.

También puede argüirse que el tono de Arendt, bastante más moderno en las humanidades, en general, y en el cauce de la crítica y el artículo de posicionamiento culturales, en particular, que en el de la erudición cientificista, no eran sino una manera de autoafirmarse como pensadora, reivindicando una dignidad que había sido

6 Trato de establecer un diálogo constante, aunque no cite algún pasaje concreto, con la obra de Marina Garcés y la idea de "mundo común”. En este caso, por ejemplo, Garcés (2015, p. 233). 
pisoteada entre los pertenecientes y las pertenecientes al pueblo judío -teniendo en cuenta que tales afirmaciones eran dignas de matización en nuestra autora, sometidas frecuentemente a su escrutinio. En 1948 podemos encontrar el tono del que hablamos, cuando Arendt expresa sus reparos al movimiento sionista. Utiliza la ironía (que puede ser autoironía, si pensamos no muy erróneamente que ella misma se incluye entre "los pocos antisionistas recalcitrantes, a quienes nadie puede tomar muy en serio") para referirse al hecho de que "no hay actualmente ninguna organización y casi ningún judío individual que no apoye en privado o en público la partición y el establecimiento de un Estado judío" (2005, p. 81). El estilo cáustico, antes que frívolo, de Arendt, extiende el distanciamiento all-pervading con el fin de traer a la arena de la discusión, el debate y el mero juego lingüístico, a aquellos conceptos que habían quedado desvanecidos entre el trauma y la religiosidad connotada. "Expiación", "culpa", "mal radical", "traición”y tantos otros conceptos que Arendt hace centro de sus profundos análisis nos recuerdan que el humanismo y la teología positiva ya habían luchado contra el miedo que alejaba a la cultura de todo aquello que había terminado convirtiéndose en dogma (Habermas 2015, p. 178).

Tampoco pretendía seducir a otro público que no fuese a una humanitas sojuzgada en la eternidad. En el capítulo dedicado e Benjamin en su libro Hombres en tiempos de oscuridad, rescata la cita de este, procedente de "La tarea del traductor", según la cual "ningún poema está escrito para el lector, ningún cuadro para el espectador, ninguna sinfonía para el oyente" (Arendt 2017b, p. 210). Ante ello comenta Arendt: "lo que más le importaba era evitar cualquier cosa que pudiera ser una reminiscencia de la empatía, como si un cierto tema de investigación tuviera un mensaje que se comunicaba por sí mismo" (ibidem). A los estudiantes de hoy se nos invita a pensar teleológicamente, y a compartir un mismo horizonte de sucesos con nuestros posibles lectores. Sin dejar al margen de esta ecuación los miedos del liberalismo, ello acaba produciendo una investigación corrompida por la utilidad técnica y el interés, al margen de cualquier gratia et amore:

Detrás de la reticencia a juzgar se oculta la sospecha de que nadie es un agente libre, y de ahí la duda de si todo el mundo es responsable o se puede esperar que responda por sus actos. En el momento en que se suscitan cuestiones morales, aunque sea de pasada, quien las suscite se verá enfrentado con esa temible falta de autoconfianza y, por ende, de orgullo, así como con una especie de falsa modestia que, cuando dice, ¿quién soy yo para juzgar?, quiere decir, en realidad, 'todos somos por el estilo, igual de malos' (Arendt 2014, p. 51).

Tengamos en cuenta que Arendt valora la revolución y las palabras que la originan como un tesoro que aparece y desaparece, a lo largo de los tiempos, en extrañas circunstancias (Birulés 2007: 111). En esa obra controvertida sobre la compasión (Sobre la revolución), unas revoluciones son buenas (la norteamericana) y otras despeñan sus posibles virtudes durante su ejecución. Esta dualidad es útil a la hora de entender que, para Arendt, las palabras deben estar protegidas por medio del tono, capaz de transmitir un pensamiento -y por tanto una "actuación"- allá donde solo había un "sepulcro", o un significante-, tal y como recoge en su comentario a Heidegger (Arendt 2016, p. 413). 
Arendt había puesto el dedo en la llaga al advertir los cambios exagerados de la opinión pública, desde el silencio o la ayuda cómplice, a la condena masiva: "La cuestión moral surgió únicamente con el fenómeno de la 'coordinación', es decir, no con la hipocresía inspirada por el miedo, sino con ese afán ya muy temprano de no perder el tren de la Historia, con ese, por así decir, sincero y repentino cambio de opinión que afectó a la gran mayoría de las figuras públicas en todos los vericuetos de la vida" (Arendt 2014, p. 54). Este es el "giro" en el que la barrera, o la "Cura", si se prefiere decir de este modo, falló a la hora de protegernos del futuro. Sencillamente, desapareció la vida del compromiso, en la que los seres humanos eran empujados a algún tipo de acción: de repente, la inacción, la ausencia de pensamiento, la ausencia de deudas respecto al futuro (Arendt 2016, p. 418). Si el pasado reciente era un ejemplo de que estos cambios eran posibles, también eran un ejemplo de su devenir y su repetición. No por otro motivo se la acusaría de utilizar actitudes y tonos peligrosos, conmocionantes, al hurgar en los procesos de culpa y acusación. Esos críticos sinceros partían de la idea de que sin pensamiento no hay culpa. Si se analiza la sociedad de crisis en la que vivimos actualmente se puede llegar a una conclusión parecida a la de Hannah Arendt de que "los miembros más respetados, diferenciados y representativos de la comunidad eran unos imbéciles y de que todos los poderes existentes eran no tanto malos como igualmente estúpidos y fraudulentos" (Arendt 2006, p. 443). Hoy parece claro que el método de escape a este tipo de mecanismos de control dialéctico es la otredad, la desproporción, el salvajismo, en aras de una felicidad radical que parece olvidada. Mientras el ser humano no alcance tal liberación, cuando menos, sería preciso entrar en el combate. Ese "ser", nos aclara el autor de La anomalía salvaje, utiliza la dignidad tranquila de la razón, el deseo, el pensamiento y la acción, con el fin de neutralizar el veneno de la destrucción (A. Negri 2011, p. 36). Aunque, como bien saben platónicos y maquiavélicos, el antídoto está fabricado a partir del propio veneno. Casi con pesar diremos que los textos de Arendt siguen poseyendo una rabiosa actualidad y que sería preciso recuperar su voz, frívola y burlona, como lo es todavía la de aquellos y aquellas que se atreven a pensar y hablar.

\section{Referencias bibliográficas}

Andrés, Ramón (2015), No sufrir compañia. Escritos místicos sobre el silencio. Barcelona: Acantilado.

Arendt, Hannah (1999), Eichmann en Jerusalén. Un estudio sobre la banalidad del mal. Barcelona: Lumen.

(2005), Una revisión de la historia judia y otros ensayos, introd. Fina Birulés. Buenos Aires: Paidós. (2006), Los orígenes del totalitarismo. Madrid: Alianza.

(2014), Responsabilidad y juicio, trad. Miguel Candel. Barcelona: Paidós.

(2015), Crisis de la república, trad. Guillermo Solana. Madrid: Trotta. 
(2016), La vida del espíritu, trad. Fina Birulés y Carmen Corral. Barcellona: Paidós. (2017a), Sobre la revolución, trad. Pedro Bravo. Madrid: Alianza.

(2017b), Hombres en tiempos de oscuridad, trad. Claudia Ferrari y A. Fernández de Haro. Madrid: Gedisa.

Barth, Karl (1998), Carta a los romanos, trad. Martínez de Lapera. Madrid: BAC.

Birmingham, Peg (2017), Hannah Arendt y los derechos humanos. El dilema de la responsabilidad común, trad. Luciano Banchio. Buenos Aires: Prometeo.

Birulés, Fina (2007), Hannah Arendt. Una herencia sin testamento. Madrid: Herder. (2017), “Arendt y Sócrates. Pensar en compañía”, en Lorena Fuster, À. y Matías Sirczuk, ed., Hannah Arendt. Buenos Aires: Katz, pp. 13-36.

Forti, Simona (2017), “Arendt lectora de Marx”, en À. Lorena Fuster y Matías Sirczuk, eds., Hannah Arendt. Buenos Aires: Katz; pp. 107-130.

Garcés, Marina (2015), Filosofía inacabada. Barcelona: Gutenberg.

Greenblatt, Stephen (2012), El giro. De cómo un manuscrito olvidado contribuyó a crear el mundo moderno, trad. Juan Rabasseda. Barcelona: Crítica.

Gutiérrez de Cabiedes, Teresa (2009), El hechizo de la comprensión. Vida y obra de Hannah Arendt. Madrid: Encuentro.

Habermas, Jürgen (2015), Mundo de la vida, política y religión, trad. Jorge Seca. Madrid: Trotta.

Han, Byung-Chul (2018), Muerte y alteridad, trad. Alberto Ciria. Barcelona: Herder.

Koselleck, Reinhart (2016), Historia/Historia, trad. Antonio Gómez Ramos. Madrid: Trotta.

Lorena Fuster, À. y Matías Sirczuk, Matías, ed. (2017), Hannah Arendt. Buenos Aires: Katz.

Negri, Antonio (2011), Spinoza subversivo, trad. Raúl Sánchez Cedillo. Madrid: Akal.

Sennett, Richard (2018), El respeto. Sobre la dignidad del hombre en un mundo de desigualdad, trad. M. Aurelio Galmarini. Barcelona: Anagrama.

Sanmartín, Olga (2018), “Celáa defiende dar el Bachillerato con un suspenso: 'el peor castigo es la rebaja de la autoestima"”. El Mundo, 12 de noviembre.

Tello García, Edgar (2018), “(Contra) la compasión y la ética del sometimiento en las culturas capitalistas: Hannah Arendt y Simone Weil”, Ambigua. En prensa.

Thomä, Dieter (2018), Puer robustus. Una filosofía del perturbador, trad. Alberto Ciria. Madrid: Herder. 